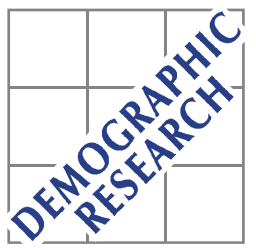

Demographic Research a free, expedited, online journal

of peer-reviewed research and commentary in the population sciences published by the Max Planck Institute for Demographic Research

Konrad-Zuse Str. 1, D-18057 Rostock · GERMANY

www.demographic-research.org

DEMOGRAPHIC RESEARCH

VOLUME 16, ARTICLE 2, PAGES 27-58

PUBLISHED 16 JANUARY 2007

http://www.demographic-research.org/Volumes/Vol16/2/

DOI: 10.4054/DemRes.2007.16.2

Research Article

\title{
A new perspective on population aging
}

\section{Warren C. Sanderson}

Sergei Scherbov

\section{(C) 2007 Sanderson \& Scherbov}

This open-access work is published under the terms of the Creative Commons Attribution NonCommercial License 2.0 Germany, which permits use, reproduction \& distribution in any medium for non-commercial purposes, provided the original author(s) and source are given credit.

See http:// creativecommons.org/licenses/by-nc/2.0/de/ 


\section{Table of Contents}

1 Introduction $\quad 28$

2 Prospective age 31

3 The relationship period and cohort prospective ages in theory 33

$4 \quad$ Historical examples of population aging from Sweden and England 36 and Wales

$5 \quad$ Population aging in the future $\quad 40$

$6 \quad$ The recent history of aging in developed countries 43

$\begin{array}{lll}7 & \text { Old age dependency ratios } & 48\end{array}$

$\begin{array}{llr}8 & \text { Conclusions } & 50\end{array}$

9 Acknowledgement $\quad 51$

Appendix A 53

$\begin{array}{ll}\text { Appendix B } & 56\end{array}$ 


\title{
A new perspective on population aging
}

\author{
Warren C. Sanderson ${ }^{1}$ \\ Sergei Scherbov ${ }^{2}$
}

\begin{abstract}
In Sanderson and Scherbov (2005) we introduced a new forward-looking definition of age and argued that its use, along with the traditional backward-looking concept of age, provides a more informative basis upon which to discuss population aging. Age is a measure of how many years a person has already lived. In contrast, our new approach to measuring age is concerned about the future. In this paper, we first explore our new age measure in detail and show, using an analytic formulation, historical data, and forecasts, that it is, in most cases, insensitive to whether it is measured using period or cohort life tables. We, then, show, using new forward-looking definitions of median age and the old age dependency ratio, how combining the traditional age concept and our new one enhances our understanding of population aging.
\end{abstract}

\footnotetext{
${ }^{1}$ Department of Economics and Department of History, State University of New York at Stony Brook, Stony Brook, New York, USA. World Population Program, International Institute for Applied Systems Analysis, Laxenburg, Austria.

${ }^{2}$ Vienna Institute of Demography, Vienna, Austria. World Population Program, International Institute for Applied Systems Analysis, Laxenburg, Austria.
} 


\section{Introduction}

The literature on population aging in developed countries is exploding. Serious concerns have been expressed about the challenges to current economic and social arrangements associated with an ever more elderly population. ${ }^{3}$ In contrast to the growth of interest in population aging, the concepts used in analyzing it have remained static. In Sanderson and Scherbov (2005) we presented a new forward-looking age measure. This paper explores the nature of this new approach to measuring age.

Essentially, we recognized people as having two different ages. Chronological age, or as we sometimes call it, "retrospective age", is a measure of how many years a person has already lived. Everyone of the same age has lived the same number of years. In contrast, prospective age is concerned about the future. Everyone with the same prospective age has the same expected remaining years of life.

In Sanderson and Scherbov (2005), we used the term "standardized age" for the new measure, but we now believe that prospective age is a better term. The term prospective age emphasizes the forward-looking nature of the concept. Retrospective age and prospective age are complementary measures and quantify two different aspects of aging.

Using chronological age, we are lead implicitly to think that people of the same age in different years would behave similarly, but because of life expectancy increases there are aspects of behavior where this might not be the case. For example, a 45 year old in 2050 might well behave in many ways like a 35 year old in 2000 if they had the same remaining life expectancy. It is precisely because many behaviors depend on the number of years left to live that it is important to supplement the usual backwardlooking definition of age with a forward-looking one.

Strategies of saving and investment are clearly forward-looking behaviors. Understanding them requires that we know not only how old people are, but how many years they expect to live as well. The acquisition of education is another. For instance, retired people are more likely to take courses to help them enjoy new leisure time activities if they have more expected years of life. Requests for and the provision of certain medical procedures also depend on the number of remaining years of life. One example of this is knee replacement surgery, which is now often performed on people above the age of seventy. It would not make much sense to do this if the operation did not significantly increase a person's number of years of mobility.

It is important to have a forward-looking measure of age not only because many behaviors are influenced by a person's expected remaining years of life, but because

\footnotetext{
${ }^{3}$ See, for example, Commission of the European Communities (2005), Ezrati (1997), and Kotlikoff and Burns
} (2004). 
important economic and social magnitudes depend on it as well. For example, medical expenditures are especially high in the last years of life. In forecasting these expenditures, it is important to take into consideration that, with increasing life expectancies, those last years of life happen at an ever older age. ${ }^{4}$ Forecasting medical expenditures only on the basis of (retrospective) age produces figures that are too high and could lead to erroneous policy decisions. The same is true with respect to forecasts for specific health-related items, such the need for nursing home beds.

Prospective age also helps in assessing future policies concerning the age at the entitlement to a full public pension. By computing the prospective age at the current entitlement age and holding it constant in population forecasts we demarcate the border between policies that allow an increase in the expected number of years of pension receipt and those that do not. Prospective age can also be useful in determining likely changes in the concerns of future voters. Thus, for many reasons, supplementing the concept of age with the concept of prospective age allows us to analyze aging more deeply than if we were to use only one age measure.

The aging of populations and of people have different dynamics. Surviving people must grow one year older each year. Populations, on the other hand, do not necessarily grow one year older each year. Populations can grow more than one year older, less than one year older or even grow younger with the passage of time. When age is measured as a two dimensional variable our descriptions of population aging grow more complex. With two ages to consider, populations can simultaneously grow younger according to one measure and older according to the other.

Demographers have not previously had a forward-looking measure of age, so in Section 2, we describe the new concept of prospective age. The fundamental feature of prospective age is that it is a time-horizon consistent measure, because all people with the same prospective age have the same expected number of years ahead of them, regardless of the number of years that they have already lived.

The expected number of years of remaining life that people have at a particular age is their cohort life expectancy, so it is natural to use that life expectancy concept in computing prospective age. Period life tables, on the other hand, are much more widely available than cohort ones. Unfortunately, the levels of period age-specific mortality rates are influenced by their rates of change making them less easily interpretable. ${ }^{5}$

If period and cohort prospective ages produced different pictures of population aging, the usefulness of the concept of prospective age would be limited. On the other hand, if the implications for understanding population aging were fundamentally the

\footnotetext{
${ }^{4}$ See for example Miller (2001), Yang et al. (2003), Seshamani (2004), Stearns and Norton (2004), and Zweifel et al. (2004).

${ }^{5}$ See Bongaarts and Feeney (2002), Bongaarts and Feeney (2003), and Horiuchi (2005).
} 
same regardless of whether period or cohort life tables were utilized, we could apply the concept of prospective age to the entire range of countries that had a suitable time series of period life tables.

So, in Section 3, using formulas in Goldstein and Wachter (2005) based on a special case of a Gompertz model of adult mortality, we derive analytic results for the relationship between period and cohort prospective ages. We show there that, in this special case, period and cohort prospective ages are almost identical.

In Section 4, we present a historical perspective on population aging using both median ages and prospective median ages. We present calculations for Sweden from 1800 to 1945 and for England and Wales from 1868 to 1941. The terminal dates of the periods were determined by availability of the most up-to-date cohort life table when the data were downloaded. Two conclusions clearly emerge. First, adding prospective median age to the (retrospective) median age in analyzing aging histories does indeed produce interesting new observations. Both countries, for example, experienced periods when they were growing older as indicated by increasing median ages and when they were growing younger as indicated by their decreasing prospective median ages. They also experienced intervals when they were growing older according to both median age measures. Second, prospective median ages are again remarkably similar regardless of whether they are computed using period or cohort life tables.

In Section 5, we turn from looking at the aging histories of Sweden and England and Wales to peering into the future of aging in the United States through 2050. We do this by assuming two different patterns of mortality change: (1) the slowing of life expectancy gains assumed by the United Nations, and (2) the continuation of the current speed of life expectancy increase observed in low mortality countries. Despite a significant increase in the median age of Americans, their prospective median age changes very modestly if at all. As in the previous two sections, we find only minor differences between prospective median ages depending on whether cohort or period life tables are used in their computation.

In Section 6 we present the recent histories of population aging in 28 countries for which information was available in the Human Mortality Database using the median age and the prospective median age computed using period life tables. By means of three comparative histories, Denmark/Norway, Belgium/Netherlands, and Austria/Hungary, we show that trends and variations in prospective median ages are different enough from those of median ages to recommend their joint use.

In Section 7, we look at another commonly used measure of age structure, the old age dependency ratio. This is frequently defined as the ratio of the number of people $65+$ years old to the number of people in the working ages. It is used for a number of purposes including indicating the number of pensioners per person of working age to the more amorphous notion of the burden of old age dependency. With increases in life 
expectancy and changes in the normal pension age, the conventional old age dependency ratio is being asked to do too many things. Here we present a new definition of the old age dependency ratio where "old age" is defined as having a prospective age of 65 instead of a retrospective age of 65 . Using population forecasts for the Germany, Japan, and the United States, we show that the new ratios are frequently quite different from the conventional old age dependency ratios. Section 8 contains some concluding thoughts.

\section{Prospective age}

Imagine two people, one alive in 1950 and the other in 2000. If these two people both were 40 years old (or alternatively had a retrospective age of 40), then naturally each would have lived 40 years by those two dates. People who share a prospective age, on the other hand, share a remaining life expectancy. If a 40 year old person in 1950 had a remaining life expectancy of 30 years, and a 50 year old person in 2000 also had a remaining life expectancy of 30 years, then the 50 year old in 2000 would have a prospective age of 40, using 1950 as a standard. In this example, we call 2000 the index year to indicate that it is the year with which we are concerned.

Figure 1 shows diagrammatically how this prospective age is derived. The leftmost pair of figures shows two columns of a life table for a person of age $a$ in the index year. The first column contains the person's age and the second the life expectancy at that age. The right-most pair also shows two columns of a life table, but they are written as the mirror-image of the first two. The last column contains an age of a person in the standard year, and the next-to-the-last column contains the life expectancy of people of that age. The prospective age of a person of age $a$ in the index year is the age in the standard year, denoted by $A$ in the Figure, such that the remaining life expectancy of a person of age $a$ in the index year is the same as the remaining life expectancy of a person of age $A$ in the standard year.

In Sanderson and Scherbov (2005), we considered two alternative measures for supplementing retrospective age: (1) prospective age and (2) the expected number of years of remaining life. Ryder (1975) was the first to suggest the use of expected remaining years of life. Indeed, Ryder went one step further. In the discussion of the definition of old age, he recommended that some particular life expectancy (10 years, in his example) be taken and that old age be assumed to begin at the age corresponding to that life expectancy. In our terminology, Ryder suggested that old age should be defined to begin at some fixed prospective age. We follow this suggestion in Section 7 below. He did not take the next step and suggest that each person has both a retrospective and 
prospective age. Ryder's paper analyzed relationships in stationary populations, so the difference between cohort and period mortality rates did not arise.

Another contribution, which anticipated the concept of prospective age, could be found in Hersch (1944). Hersch defined "potential life years" as the average remaining life expectancy of members of a population (see Panush and Peritz (1996)). Imagine for a moment that instead of computing the average remaining life expectancy, we computed the median using period mortality rates that varied over time. If we took this variant of Hersch's potential life years and looked up the corresponding value of age in a period life table for the standard year, we would get our period prospective median age. An analogous procedure using cohort life tables would yield our cohort prospective median age.

Using prospective age has one distinct advantage. As we show in the following three sections, prospective age is generally insensitive to whether it is computed using period or cohort life tables. This is not the case when we use remaining life expectancies. This may seem counterintuitive at first and that is why we demonstrate it in three quite different ways, using an analytic formulation, historical data, and forecasts. In an era of increasing life expectancies, the period and cohort life expectancies of an individual can be quite different. In contrast, prospective age calculated using period and cohort life tables differ significantly only in unusual circumstances, such as the influenza epidemic of 1918.

In the example above, we could simply say that someone aged 50 in 2000 and someone aged 40 in 1950 share the same period life expectancy (30 years) and thus that in the intervening half century the age at which a person has a life expectancy of 30 years has risen from 40 to 50 . This is a perfectly fine alternative to the more formal language that we used above, with its use of index and standard years. But it refers only to period life expectancies. Now let us retell the story using cohort life expectancies. Suppose someone aged 40 in 1950 shared the same cohort life expectancy with an individual in 2000 . How old would that individual be? We show in this paper that the person in 2000 would be about 50 years old as well, even though their shared cohort life expectancy will, in general, be higher than their shared period life expectancy. The insensitivity of the age of person in 2000 (50 years old in this example) to whether it is computed using period or cohort life tables is a major asset for the study of population aging. Nevertheless, we do not mean to argue here that the use of prospective age should preclude the use of remaining life expectancies. Some people find it more natural to think in terms of ages and some in terms of remaining years of life expectancy. The general point is that it is more informative to analyze aging by combining both a backward-looking and a forward-looking age measure. 
Figure 1: Diagram Showing How Prospective Age is Determined

\begin{tabular}{|l|l|}
\hline Retrospective Age & $\begin{array}{l}\text { Remaining Life } \\
\text { Expectancy }\end{array}$ \\
\hline$a$ & $\operatorname{RLE}_{a}^{\text {index }}$ \\
\hline
\end{tabular}

Life Table of Index Year

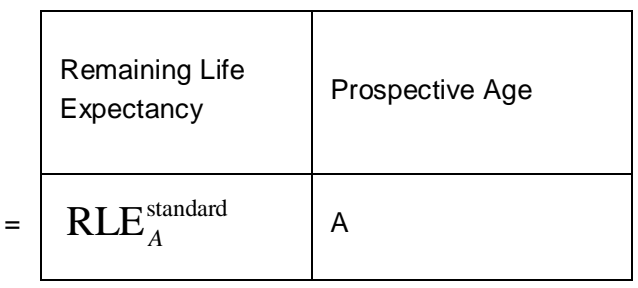

Life Table of Standard Year

\section{The relationship period and cohort prospective ages in theory}

In this section and the following two, we demonstrate that prospective age is, except in unusual circumstances, rather insensitive to whether it is measured using period or cohort life tables. We do this using three different techniques. Here we present a simple analytical model and explicitly derive the result. Simple models do not always correspond closely to the reality that they try to mirror. So in the next section, we look at long-run historical data and show this insensitivity also is present there. In the following section, we look at population forecasts and show the same thing. We do not rest our case regarding the insensitivity on a single type of analysis. It is the consistency of all three types that bolsters our argument.

If period and cohort prospective ages were very different from one another, then we would always have to face the question of which one is better to use. Since they are close enough to one another, we generally do not need to worry about this.

It is helpful to begin our study of the difference between period and cohort prospective ages with some mathematical notation. Let $e_{p}(a, t)$ be life expectancy at age $a$ in year $t$ calculated using period life tables and $e_{c}(a, t)$ be the life expectancy of people of age $a$ in year $t$ computed using cohort life tables. Both refer to people born in the year $t-a$, but in the first case remaining life expectancy is computed using the mortality rates in period $t$ while in the second we use the cohort mortality rates after year $t$ of the people born in year $t-a$.

Using this notation, the period prospective age of a person of (retrospective) age $a$ in index year $I$ (using the standard year $S$ ), which we denote by $A_{p}$, can be computed from equation (1), 


$$
e_{p}\left(A_{p}, S\right)=e_{p}(a, I)
$$

and the cohort prospective age of a person of (retrospective) age $a$ in index year $I$ (using the standard year $S), A_{c}$, can be computed from equation (2),

$$
e_{c}\left(A_{c}, S\right)=e_{c}(a, I) \text {. }
$$

Equation (1) suggests the following procedure. Look up the life expectancy of people of age $a$ in year $I$ using a period life table. This is the number on the right-hand side of equation (1). Next, go to the period life table for year $S$. The age in that life table that produces the same life expectancy we just found for people of age $a$ in year $I$ is $A_{p}$, the period prospective age. The cohort prospective age is found using the same process, except that cohort life tables are used instead of period ones.

Goldstein and Wachter (2005) present formulas for the remaining life expectancies at adult ages computed using period and cohort life tables. These formulas allow us to write down simple equations that relate retrospective and prospective ages when the two types of life tables are used. ${ }^{6}$ The assumptions underlying the Goldstein-Wachter results are simplifications that are sometimes closer and sometimes farther from observed patterns of mortality rates. Nevertheless, even though they are derived only for a particular model of adult mortality, the equations for period and cohort prospective ages provide us with insight into their relationship that cannot be gained in any other way.

Equations (3) and (4) have been computed using equations (A3) and (A7) in Appendix A, and data for Swedish females, setting (retrospective) age, $a$, equal to 27, the index year, $I$, equal to 1830 , and the standard year, $S$, equal to $1930 .^{7}$

$$
A_{p}=27+0.111 \cdot(S-I)
$$

and

$$
A_{c}=27+0.118 \cdot(S-I)
$$

\footnotetext{
${ }^{6}$ The derivation of the relationships between retrospective and prospective ages based on the equations in Goldstein and Wachter (2005) appears in Appendix A.

7 The data are from the Human Mortality Database downloaded on March 1, 2005.
} 
Both equations have two additive terms on the right-hand side. The first terms are always equal to (retrospective) age $a$ (in this case, 27). The only difference between period and cohort prospective ages arises because of the difference in the coefficients of $(S-I)$ in the second terms. We show in the Appendix that these differences are always small, and therefore, period and cohort prospective ages are always reasonably close to one another.

In this example, where 100 years separate the standard and the index years, the empirical period prospective age of 27 year old Swedish women in 1830 is 38.1 (using 1930 as the standard year) and their empirical cohort prospective age is 39.0, 0.9 years higher. The formulas in Goldstein and Wachter imply that the cohort prospective age would be 0.7 years higher. This is quite a close approximation to what we observe.

Perhaps an analogy can sharpen our intuition about prospective age. Imagine that we had a paragraph written in English and that we first translated it into German and then back into English. Next, we took the same paragraph and translated it into French and then again back into English. This is similar to what we do when we compute prospective age. When we calculate it on the basis of period life tables, we translate (retrospective) age, $a$, into remaining life expectancy in year $I$. Then we translate that remaining life expectancy back into the prospective age using the period life table for year $S$. This translation forward and then backward, is like translating the paragraph from English to German and then back again. In this example, doing the same thing using French is the parallel of doing the computation with cohort life tables.

The English text when translated into German looks very different from the text in French, just like remaining life expectancy is very different depending on whether it is measured using period or cohort life tables. But when both the German and French texts are translated back into English, we get a much more similar result than we had before the reverse translation. The same is true with respect to period and cohort prospective ages. Both involve a forward translation from age to life expectancy and then a backward translation from life expectancy to age. The forward and the backward translations are made using consistent types of life tables. Although the results of the first translation from age to life expectancy are different depending on whether period or cohort life tables are used, those differences are largely undone when the same sort of life tables are used in reverse.

The analytic approach used in this section (based on Gompertz mortality rates) provides us with some broad insights into why period and cohort prospective ages are similar. But the model does not take into account severe epidemics and other deviations from its assumptions that we observe in the data. To see how similar period and cohort prospective ages are in reality, we turn now to consider historical data from Sweden and England and Wales. 


\section{Historical examples of population aging from Sweden and England and Wales}

One common measure of population aging is the increase in the median (retrospective) age of its members (Gavrilov and Heuveline 2003). We have been arguing in this paper that demographers need to think about age as a two dimensional concept, incorporating both retrospective and prospective ages. It follows from this that we also need to think about population aging in two dimensions, using both the retrospective median age and the prospective median age of the population.

The median age of a population is the age that divides the population into two numerically equal groups. The prospective median age is defined as the prospective age of a person at that median age. For example, if the median age of a population in 1950 was 30 and the prospective age of a 30 year old in that year was 35 (using the year 2000 as a standard), then the population's prospective median age in 1950 would be 35 (given the standard year of 2000). With one clarifying assumption, everyone in a population can be assigned a prospective age. ${ }^{8}$ In that case, the prospective median age is identical to the median of the population members' prospective ages.

In Figure 2, we graph the median age of the Swedish population from 1800 to 1944. This is supplemented with the prospective median age calculated using period and cohort life tables (Human Mortality Database, 2005). The median age of the Swedish population was 26.2 in 1800 . It remained roughly constant for two decades and then declined to 24.1 in 1838. Subsequently, it increased slowly, reaching 26.3 in 1900 and 27.7 in 1920. After 1920 the median age began to rise rapidly, hitting 33.0 in 1940.

From the vantage of the prospective median age, the history looks quite different. Using 1930 as the standard year, the prospective median age was around 40 in 1800 and fell, sometimes more rapidly, sometimes more slowly, until the mid-1920s when it began a slow rise. Over the period 1800 to 1946, the median (retrospective) age of the

\footnotetext{
${ }^{8}$ The median age is the median of people's retrospective ages. Therefore, the terms "retrospective median age" and "median retrospective age" refer to the same concept and can be used interchangeably. The situation with respect to prospective ages is a bit more complex. When the index year is later than the standard year, a remaining life expectancy at a young age may be so high that there is no age in the standard year with a corresponding life expectancy. In these cases, we assign a prospective age equal to the age in the standard year that has the highest remaining life expectancy. Once this is done, every person in the index year has a corresponding prospective age and we can appropriately speak of a median prospective age. In this case, the median value of all the prospective ages is identical to prospective age of people in the population who are at the median retrospective age. This allows us to use the terms "prospective median age" and "median prospective age" interchangeably.
} 
Swedish population increased by around 8 years. Over the same period, the prospective median age decreased by around 9 years. ${ }^{9}$

The period prospective median age in some year, for example 1900, is the age of a person in 1930 who had the same remaining life expectancy as the median aged person in 1900, both computed from period life tables. For ease of exposition, let us round the median age in 1900 to 27 . To find the period prospective age of someone 27 years old in 1900, using 1930 as a standard, we would look up the remaining life expectancy of a 27 year old in 1900 and find the age of a person in 1930 who had the same remaining life expectancy, using period life tables in both instances. To find the cohort prospective age of someone 27 in 1900, using 1930 as a standard, we would look up the remaining life expectancy of a 27 year old in the cohort life table of those born in 1873 . The cohort prospective age would be the age of a person in 1930 whose cohort had the same remaining life expectancy. Note that the cohort life expectancies of those born in 1873 , from birth through age 45, were all influenced by the Spanish flu epidemic of 1918.

Figure 3 is similar to Figure 2 except that it deals with England and Wales. For ease of comparison, we have drawn the two graphs on the same time scale, even though the series for England and Wales is shorter. In 1841, the median age in England and Wales was 22.4, 1.7 years younger than in Sweden. In the subsequent one hundred years, aging was more rapid in England and Wales. The median age there increased by 12.1 years, but only by 8.6 years in Sweden. As with Sweden, most of the increase in the median age happened after the mid-1880's. The prospective ages both fall from 1864 through the first decade of the twentieth century and then begin to increase slowly.

In Figures 2 and 3, we see an upward spike in the period prospective ages in 1918, the year of the Spanish flu epidemic..$^{10}$ Remaining life expectancies at the median ages in 1918 were low relative to nearby earlier and later years. These unusually low life expectancies correspond to unusually high ages in the standard year, 1930.

While the Spanish flu epidemic affected period prospective ages in 1918, it influenced cohort prospective ages over an entire generation. People born in 1848, for example, experienced strong increases in their morality rates in 1918, when they were 70 years old. Cohort life tables for all groups affected by the epidemic show lower remaining life expectancies in the years prior to 1918 than they would have shown in

${ }^{9}$ Median age and prospective median age coincide in the standard year. Changes in the standard year raise or lower the curve of prospective median age, but have little effect on slope of that curve.

${ }^{10}$ In 1809 there was also a spike in the period prospective age in Sweden. It was associated with the war between Russia and Sweden that was going on at the time. Smallpox was an important cause of death around this time, but the increase in wartime deaths was mainly due to an increase in acute gastroenteritis (Torres Joerges and Núñez Garcés (nd)). 
the absence of the epidemic. When the standard year is after 1918, as it is in the two Figures, the lower remaining life expectancies are reflected in cohort prospective ages that are higher than they would have been had there been no epidemic. The Gompertz model in the previous section makes no allowance for severe epidemics and it is not surprising that they can cause the sorts of differences in the trends of the period and cohort prospective ages that we see here.

Like Sweden, England and Wales also experienced a prolonged period of rising median retrospective ages and falling prospective ages. Although there are some differences, one clear conclusion from Figures 2 and 3 is that, in the long-run, prospective ages using period and cohort life tables follow nearly the same paths. The inferences that we would make regarding the historical patterns of aging are largely independent of which type of prospective age measure we use.

In interpreting Figures 2 and 3 it is important to observe that the relationships between the three curves depend on the standard year chosen. Both prospective age curves intersect the median age line in the standard year. The choice of the standard year essentially causes fixed upward or downward shifts in the two prospective age curves to ensure that they both intersect the median age line in the standard year. We discuss this in Appendix B. Thus, in general, changes in prospective ages are robust to differences in standard year, but their levels are not.

In choosing a standard year, it is best to choose periods and cohorts with close to typical mortality patterns, so that unusual mortality experiences are not incorporated into the standard. There are a number of ways of doing this. For example, we could look for years in which period and cohort life expectancies were close to their five-year moving averages. Alternatively, we could use life expectancies based on smoothed mortality rates. 
Figure 2: Sweden: Median Age and Prospective Median Ages Computed with Period and Cohort Life Tables, 1800-1944

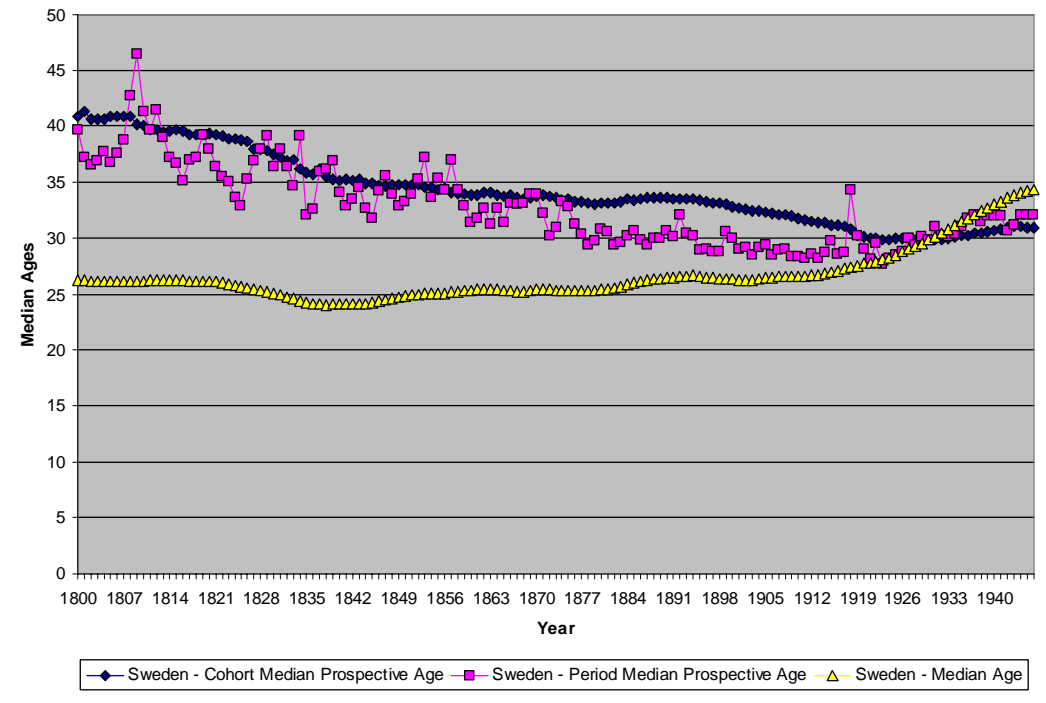

Figure 3: England and Wales: Median Age and Prospective Median Ages Computed with Period and Cohort Life Tables, 1869-1941

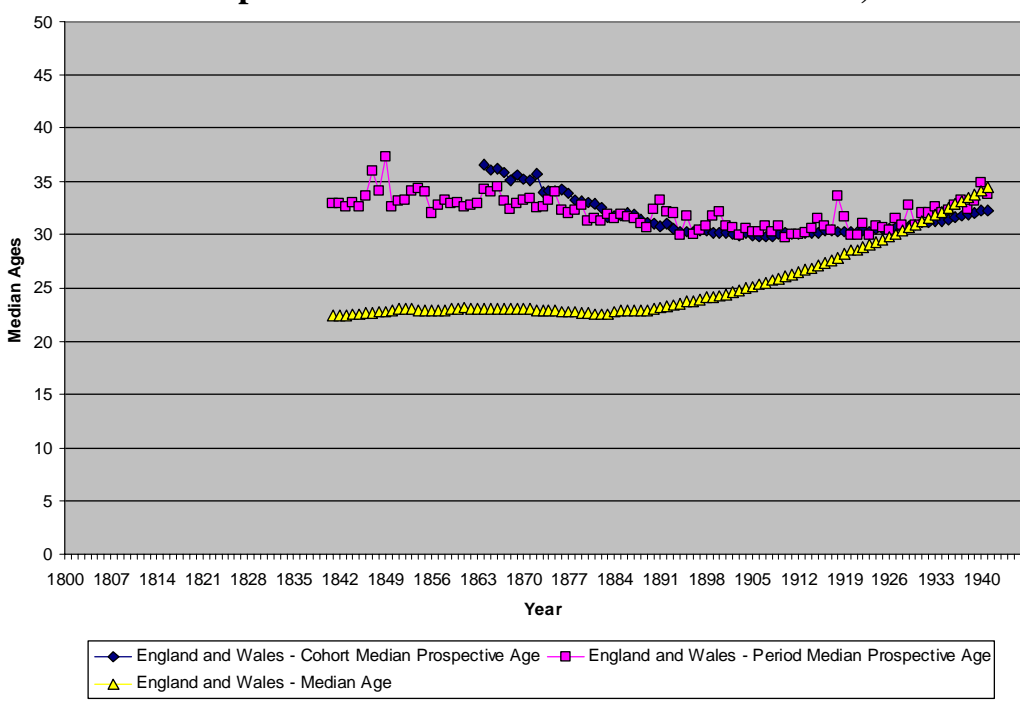




\section{Population aging in the future}

In the past, mortality changes did not correspond exactly to the simple Gompertz model discussed in Section 3, but nonetheless prospective ages computed using period and cohort life tables were quite similar. In this Section, we briefly look into the future in order to see whether the kinds of mortality changes that we forecast are also likely to produce prospective median ages that are insensitive to whether cohort or period life tables are used. Here we use the United States as our example. Our procedure is (1) to forecast mortality rates ${ }^{11}$, (2) to create period and cohort life tables, and (3) to compute prospective median ages using both sorts of tables. Two different life expectancy forecasts are used, the United Nations forecasts and one based on the assumption that life expectancy at birth would increase by 0.2 years per calendar year. The later is about the average increase experienced in high life expectancy countries since $1960 .^{12}$

Figure 4 shows the evolution of the median age of the US population and two prospective median ages using the UN assumptions about the course of future mortality rates. In this example, the median age rises from 36.3 years in 2000 to 42.7 years in 2050. The rise in median age is initially more rapid and, after the mid-2030s, much slower. As expected, prospective ages show a slower increase. When measured using period life tables, the prospective median age rises from 36.3 years in 2000 to 38.5 years in 2025 and then falls to 38.3 years in $2050 .{ }^{13}$ Using cohort life tables, it increases from 36.3 years in 2000 to 38.3 in 2025 and then increases to 38.9 in 2050. The difference in the two prospective ages in 2050 is only 0.6 years. Further, both series reach a peak in 2036. Clearly, in this example, perspective age and the kinds of inferences that we might make from its path are not sensitive to whether period or cohort life tables are used.

Figure 5 is the analogous figure using instead the assumption that US life expectancy at birth will increase by 0.2 years with the passage of each calendar year.

\footnotetext{
${ }^{11}$ Mortality rate forecasts were made using a Brass relational model. We fit the forecasts of life expectancy at birth by changing one parameter, the intercept. For the standard we used the most recent age-specific mortality schedule. We have done extensive experimentation with two parameter Brass models where the relationship between the two parameters was estimated using historical data. Simulations show that the results observed with regard to the relationships between period and cohort median ages differ little from the ones shown here.

${ }^{12}$ Oeppen and Vaupel (2001) found that female best practice life expectancy increased consistently by an average of 0.25 years per calendar year over the last one and a half centuries. Sanderson and Scherbov (2004) showed that the average life expectancy increase in a group of low mortality countries from around 1960 to around 2000 was about 0.20 years per calendar year. The assumption of a 0.20 year increase, on average, in life expectancy at birth was used in creating mean forecasted mortality paths in the probabilistic population forecasts in Lutz et al. (2001), Lutz et al. (2004), and Sanderson and Scherbov (2005).

${ }^{13}$ The year 2000 is used as the standard in these examples.
} 
This is a faster pace of improvement than assumed by the UN and it results in a higher US median age in 2050, 2.4 years more than when the UN life expectancies were used. Using period and cohort life tables, the prospective age is roughly constant from 2000 to the late 2030s after which it falls. The prospective median age in the US in 2050 computed on the basis of period life tables is 35.9 years. When measured using cohort life tables it is 1.2 years lower. In this example as well, it is evident that the story of aging that we obtain using the prospective median age derived either from period or cohort life tables is essentially identical.

In the case of a constant annual increase in life expectancy at birth, the prospective median age derived from period life tables always lies above that created using cohort life tables. In a world in which the populations of most countries are aging, this observation can be useful because it means that the extent of aging, as measured by prospective median ages computed from cohort life tables, is always less than we would calculate it to be using the more readily available period life tables. Because period prospective median age lies slightly above cohort prospective median age, we can be confident that in using period prospective age we do not overestimate the extent of aging.

These examples are not a test of whether future prospective ages will be the same, regardless of whether they are measured on a cohort or period basis. We cannot possibly know this. But this is not the question that we are addressing here. The thesis of this paper is that we can understand population aging better if we use both the median age and the prospective median age together. With respect to the prospective age, it does not matter much whether we use the variant based on cohort life tables or the one based on period life tables. We get the same results either way. We have now adduced three quite different types of evidence for this: (1) a theoretical model, (2) historical observations, and (3) two forecasts. They all consistently show only relatively small differences between prospective ages based on period and cohort life tables. This allows us to move on to the next Section, where we investigate recent patterns of aging using both the median age and the prospective median age based just on period life tables. 
Figure 4: US: Median Age and Prospective Median Age Computed with Period and Cohort Life Tables, 2000-2050, Based on United Nations Life Expectancy Assumptions

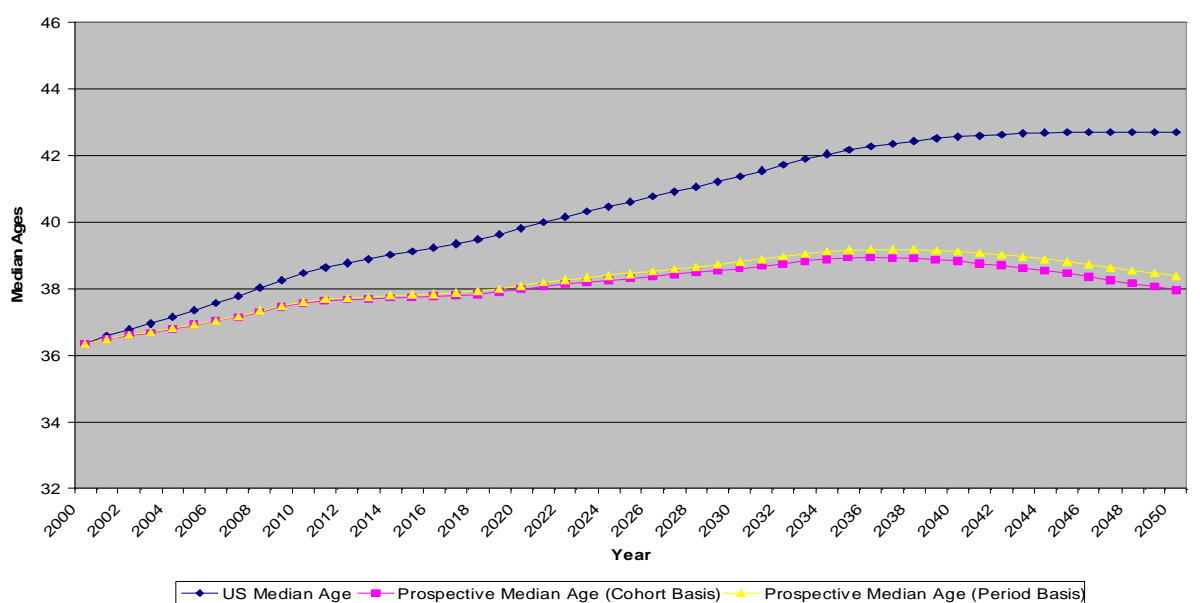

Figure 5: US: Median Age and Prospective Median Age Computed with Period and Cohort Life Tables, 2000-2050, Based on the Assumption that Life Expectancy at Birth Increases by 0.2 Years per Calendar Year

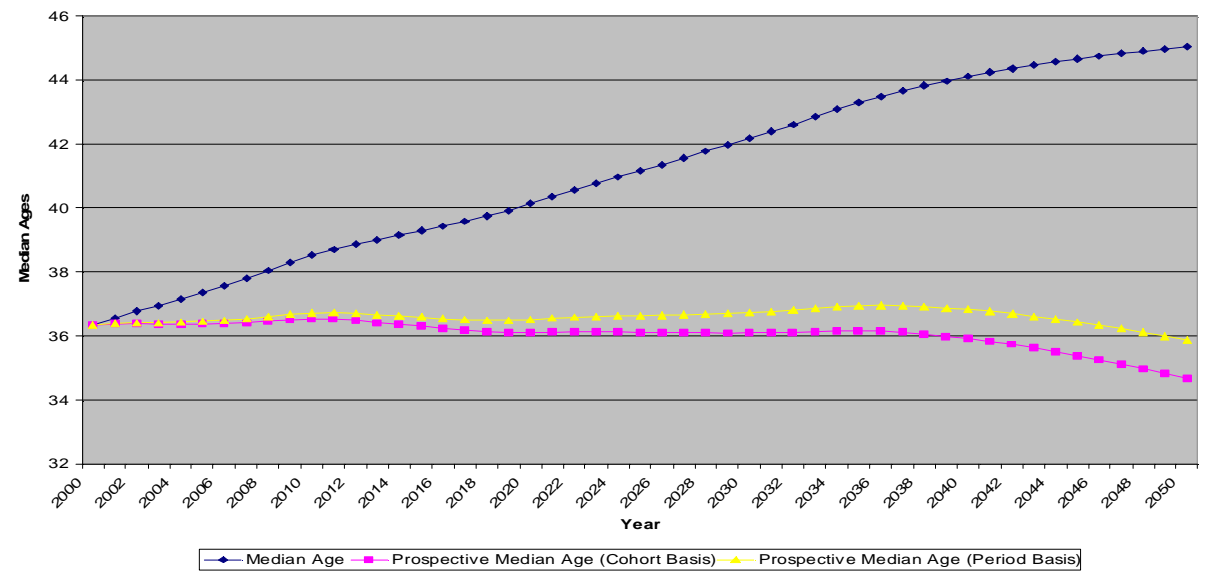




\section{The recent history of aging in developed countries}

In this Section, we demonstrate that the prospective median age incorporates enough additional information to make it a useful complement to the median age in studying histories of population aging. Table 1 contains median ages and prospective median ages for the female populations of 28 countries currently in the Human Mortality Database for 1950, 1960, 1975, and 2000, using period life tables. As we showed above, prospective ages computed using period and cohort life tables tend to be quite similar and give the same broad inferences with respect to population aging. In any event, it is impossible to produce the numbers in Table 1 using cohort life tables, because the required tables do not exist yet. The Table is produced using the life table for England and Wales in 1980 as a standard. By using a particular country's life table as a standard, prospective ages are commensurate across countries. In other words, every person with a prospective age of 35 has the same remaining life expectancy as a 35 year old in England and Wales in 1980.

Because of increasing life expectancies, prospective median ages rise less rapidly than median ages. Japanese females had the fastest increase in their median age, going from 23.0 years in 1950 to 43.0 years in 2000. The increase in their prospective median age was much smaller, rising from 32.7 years in 1950 to 35.7 years in 2000. But Japan did not have the fastest increase in its prospective median age. That distinction goes to Russia. The Russian female population was young in 1960, with a median age of 30.4 years. Its prospective median age, at that time, was 31.8 years, 1.2 years above Japan's at that time. Over the subsequent four decades, Russia's prospective median age rose to 42.5 years, 6.7 years higher than Japan's.

Iceland and New Zealand are the youngest countries in the Table in 2000 both in terms of median age and prospective median age. Neither were the youngest in 1950 based on their median age. Japan was younger. Iceland did, however, have the lowest prospective median age in that year. According to both the median age and prospective median age, Iceland's population grew younger from 1950 to 1975 after which it began to age. In 2000, Iceland's prospective median age was close to what it had been in 1950, although it median age was higher. Among all the countries in the Table for which there are data for 1950, Austria had the highest prospective median age. It decreased throughout the period and by 2000 its prospective median age was no longer unusual. There are many comparisons that can be made using the data on median ages and prospective median ages shown Table 1 . Here we will just focus on three historical examples: (1) Denmark and Norway, (2) Belgium and the Netherlands, and (3) Austria and Hungary. 
Sanderson \& Scherbov: A new perspective on population aging

Table 1: Median age and period prospective median age for countries in the Human Mortality Database, 1950, 1960, 1975, and 2000

\begin{tabular}{|c|c|c|c|c|c|c|c|c|}
\hline & & 1950 & & 1960 & & 1975 & & 2000 \\
\hline & $\begin{array}{l}\text { Median } \\
\text { age }\end{array}$ & $\begin{array}{l}\text { Prospective } \\
\text { median age }\end{array}$ & $\begin{array}{l}\text { Median } \\
\text { age }\end{array}$ & $\begin{array}{l}\text { Prospective } \\
\text { median age }\end{array}$ & $\begin{array}{l}\text { Median } \\
\text { age }\end{array}$ & $\begin{array}{l}\text { Prospective } \\
\text { median age }\end{array}$ & $\begin{array}{l}\text { Median } \\
\text { age }\end{array}$ & $\begin{array}{l}\text { Prospective } \\
\text { median age }\end{array}$ \\
\hline$\overline{\text { Austria }}$ & 37.0 & 41.6 & 37.9 & 40.6 & 36.2 & 37.5 & 39.3 & 35.5 \\
\hline Belgium & 36.5 & 40.8 & 36.3 & 38.8 & 36.1 & 37.3 & 40.0 & 36.3 \\
\hline Bulgaria & 27.3 & 31.5 & 30.8 & 33.2 & 34.4 & 36.7 & 41.2 & 42.7 \\
\hline Canada & 27.5 & 31.0 & 26.8 & 28.0 & 27.7 & 26.8 & 37.5 & 32.9 \\
\hline Czech Republic & 34.5 & 39.7 & 34.5 & 37.2 & 34.7 & 37.1 & 39.3 & 38.4 \\
\hline Denmark & 32.3 & 36.0 & 34.0 & 36.0 & 34.0 & 33.9 & 39.4 & 37.7 \\
\hline England \& Wales & 36.4 & 39.9 & 37.6 & 39.4 & 36.2 & 36.9 & 38.6 & 35.5 \\
\hline Finland & 29.5 & 35.1 & 30.4 & 34.0 & 32.8 & 33.5 & 40.8 & 37.1 \\
\hline France & 36.6 & 40.3 & 34.7 & 36.5 & 33.6 & 33.1 & 38.9 & 33.4 \\
\hline East Germany & - & - & 39.4 & 42.5 & 38.1 & 40.5 & 42.9 & 39.7 \\
\hline West Germany & - & - & 37.0 & 40.1 & 37.5 & 38.9 & 41.1 & 37.3 \\
\hline Hungary & 31.2 & 36.8 & 33.3 & 37.1 & 36.2 & 39.0 & 40.7 & 41.8 \\
\hline Iceland & 27.2 & 29.1 & 26.1 & 26.9 & 25.8 & 23.7 & 33.3 & 29.5 \\
\hline Italy & 29.4 & 33.3 & 32.5 & 34.7 & 35.0 & 35.2 & 41.6 & 36.5 \\
\hline Japan & 23.0 & 32.7 & 26.2 & 30.7 & 31.3 & 31.2 & 43.0 & 35.7 \\
\hline Latvia & - & - & 35.0 & 36.3 & 37.8 & 39.4 & 40.8 & 41.2 \\
\hline Lithuania & - & - & 30.3 & 31.2 & 34.0 & 34.2 & 38.2 & 37.4 \\
\hline Netherlands & 28.7 & 31.4 & 29.7 & 30.6 & 30.2 & 29.3 & 38.2 & 34.8 \\
\hline New Zealand & 29.9 & 33.4 & 28.4 & 30.1 & 26.9 & 27.6 & 34.9 & 30.7 \\
\hline Norway & 33.3 & 35.1 & 35.3 & 35.6 & 33.6 & 32.4 & 37.8 & 33.9 \\
\hline Portugal & - & - & 29.1 & 32.1 & 31.6 & 33.2 & 39.0 & 35.9 \\
\hline Russia & - & - & 30.4 & 31.8 & 35.3 & 37.5 & 39.0 & 42.4 \\
\hline Slovak Republic & 27.7 & 33.5 & 28.6 & 31.4 & 29.5 & 31.5 & 35.5 & 35.4 \\
\hline Spain & 28.6 & 33.4 & 30.6 & 32.8 & 31.6 & 31.5 & 38.8 & 33.3 \\
\hline Sweden & 34.8 & 38.0 & 36.8 & 38.2 & 36.6 & 35.6 & 40.7 & 36.2 \\
\hline Switzerland & 34.4 & 38.1 & 34.0 & 35.8 & 34.0 & 32.7 & 39.6 & 34.3 \\
\hline Ukraine & - & - & 31.9 & 32.6 & 36.7 & 38.2 & 40.2 & 43.0 \\
\hline USA & - & - & 30.4 & 32.6 & 29.8 & 29.6 & 36.5 & 33.8 \\
\hline
\end{tabular}


Figure 6 shows the median ages for Denmark and Norway. ${ }^{14}$ In 1950, Denmark and Norway had similar median ages and prospective median ages. Danish women had a slightly lower median age, 32.3 , compared to 33.4 for Norwegian women. In terms of prospective median ages, Danish women were slightly older, with a prospective median age of 36.0, 0.9 years older than their Norwegian counterparts. Since 1950, the broad movements in median ages and prospective median ages were also similar with an upward movement from 1950 to the mid-1960s, a downward movement for around the next ten years, followed by a period of renewed rise. The most striking difference is the gap that emerged between the prospective median age of Danish and Norwegian women. In 2002, the prospective median age of Norwegian women was 3.7 years younger than that for Danish women. ${ }^{15}$

A second interesting feature of Figure 6 is the relationship between median age and prospective median age during the 1990s. In both countries, median ages rose at a rate of around one year per decade. Prospective median ages, on the other hand, hardly

\section{Figure 6: Denmark and Norway: Median Age and Prospective Median Age (Period Basis) 1950-2002.}

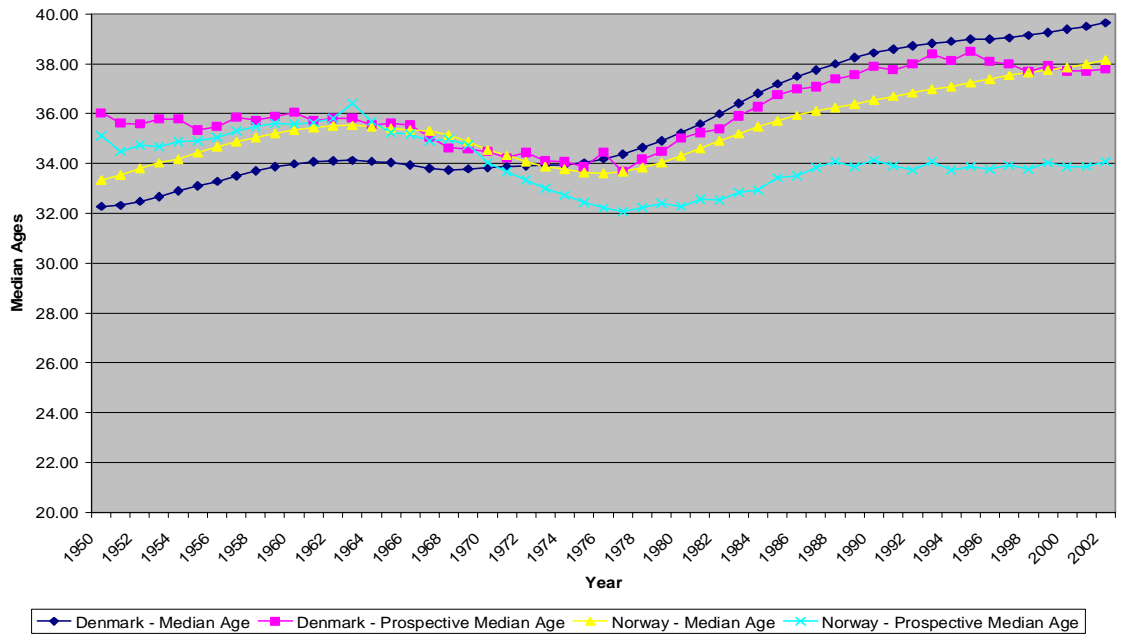

\footnotetext{
${ }^{14}$ These graphs were also drawn using England and Wales in 1980 as a standard. This would explain a feature of the graphs that might otherwise be puzzling. Using a country's life tables, median age and prospective median age are always the same in the standard year. This is not necessarily the case when a different country's life tables are used.

${ }^{15}$ This difference is mainly due to the comparatively slow increase in Danish life expectancies.
} 
budged. During this period, increases in the median age and increases in adult life expectancies had almost equal and opposite effects on prospective ages.

While the recent story of population aging in Denmark and Norway is one of divergence, the comparison between Belgium and the Netherlands in Figure 7 provides an example of convergence. In 1950, the population of the Netherlands was considerably younger than the population of Belgium. The median age of Dutch women was 28.7 in that year, 7.8 years younger than the median-aged Belgian women. By 2002, that gap was reduced to 1.9 years. In 1950, the prospective median age of Dutch women was 31.4 years, 9.4 years younger than that in Belgium. By 2002, the difference was only 1.5 years. The prospective median age fell during the period in Belgium and rose in the Netherlands.

Another interesting aspect of Figure 7 is the rapid increase in both the median age and the prospective median age of Dutch women since 1980. Such a rapid rise in both median ages is seen only in the figures for the Netherlands.

\section{Figure 7: Belgium and the Netherlands: Median Age and Prospective Median Age (Period Basis) 1950-2002.}

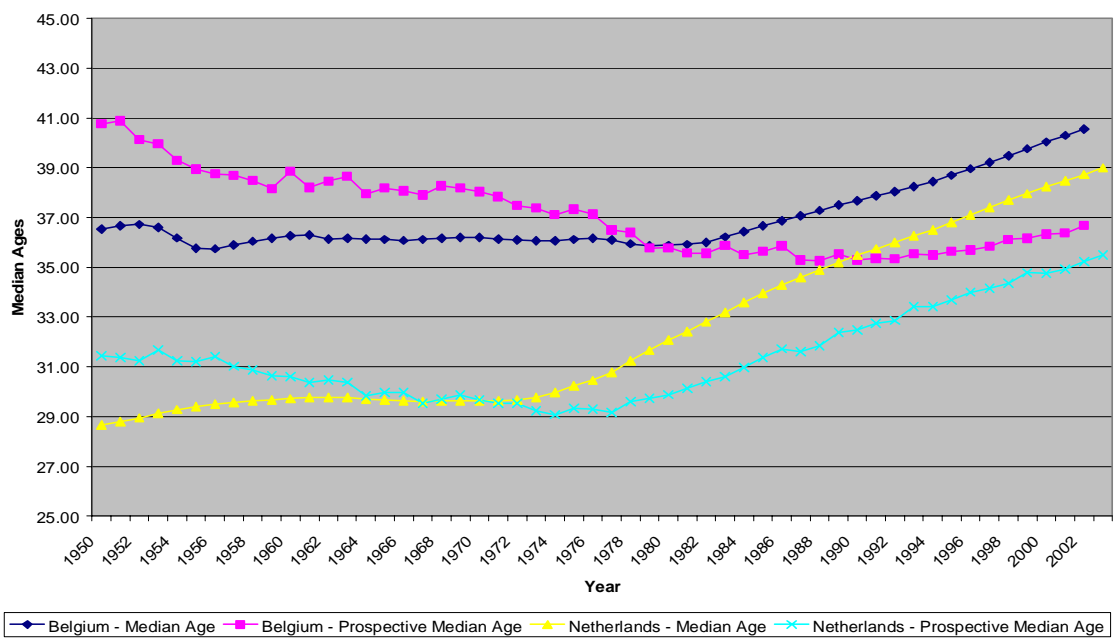

The recent aging histories of Austria and Hungary are interesting not only because they were two of the pillars of the pre-World War I Austro-Hungarian Empire, but also because of their different experiences since the end of the Second World War. In 1950, 
Austria was a comparatively old country, with a median age for females of 37.0. In contrast, Hungary was a relatively young country with a median age of 31.2. As can be seen in Figure 8, between 1950 and 2000, both countries aged. The median age rose slightly in Austria, to 39.3 in 2000 and quite rapidly in Hungary, passing Austria and reaching 40.7 in 2000.

From the vantage of prospective age, however, the history is enriched with another story. Austria, the relatively old country in 1950, experienced a half a century in which its prospective median age fell. By 2000, it was 6.1 years lower than it was in 1950 . During the same period, the prospective median age in Hungary increased by 5.0 years. In 2000, Austria had a prospective median age close to Hungary's in 1950 and Hungary had a prospective median age close to Austria's in 1950. According to its prospective median age, Austria can no longer be considered a country with a particularly old population. More countries in Table 1 have prospective ages above Austria's than have lower ones. Hungary clearly has a relatively old population. In 2000, its prospective median age was among the highest in the Table.

The comparisons that we have emphasized here are examples of how our reading of the history of population aging is enriched when both forward- and backwardlooking measures are taken into account.

\section{Figure 8: Austria and Hungary: Median Age and Prospective Median Age (Period Basis) 1950-2002.}

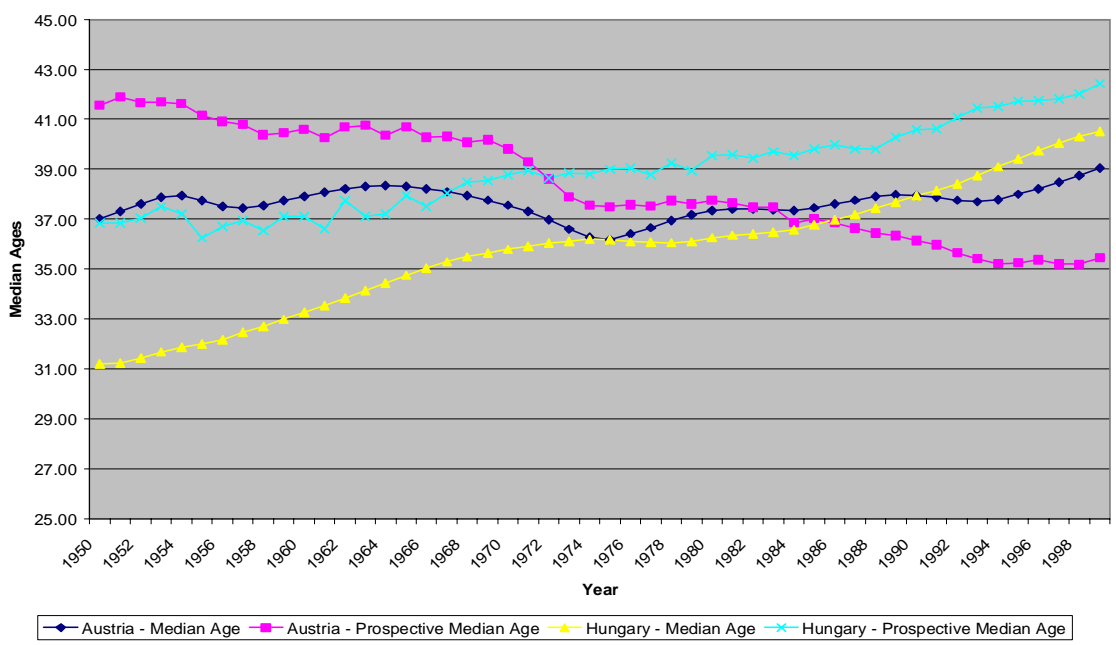




\section{Old age dependency ratios}

The change in median age is only one concept used to determine to extent of population aging. Another is the change in the old age dependency ratio. The old age dependency ratio has been used to analyze many different aspects of aging from retirement to the burden of public pensions to the more amorphous concept of old age dependency itself. With increases in life expectancy and increases in normal pension ages, one old age dependency ratio no longer suffices for all those purposes.

The old age dependency ratio is now something of a misnomer. Many people at age 65 and above are living quite independent and active lives, with incomes coming from a variety of sources including their labor income (if they are still working), their own savings and returns on their investments, and private and public pensions. Using 65 as the fixed age at the onset of "old age dependency" has already become outdated and it will become more and more anachronistic with the passage of time. Table 2 shows what happens when the age at the onset of "old age dependency" changes over time so as keep remaining life expectancy constant. By definition, this old age dependency ratio also keeps prospective age constant. Therefore, we call it the "prospective old age dependency ratio" and use the acronym POADR for it.

POADRs are specified analogously to prospective ages. To compute a prospective age, we need a retrospective age, an index year (year of interest), and a standard year. To compute a prospective old age dependency ratio, we need a prospective age, an index year, and a standard year. By varying the prospective age and the standard year, it is possible to compute POADRs that are appropriate for answering different questions.

For comparability with the conventional old age dependency ratios, the ages in column one of Table 2 are computed assuming that remaining life expectancy remains fixed at its observed value for 65 year olds in 2000. The conventional old age dependency ratio is the ratio of people at age $65+$ to those 20 to 64 . The prospective old age dependency ratio is the ratio of the number of people at prospective age $65+$ to the number of people between 20 and that prospective age. It is important to keep in mind that this is only one of the possible POADRs that can be created.

The first column in the Table shows the retrospective age at the onset of "old age dependency" for Germany, Japan, and the United States when remaining life expectancy is held fixed. All the data in the Table are derived from the probabilistic population forecasts in Sanderson and Scherbov (2005) using the mean values of the forecasted distributions of fertility, mortality, and migration.

The second column in the Table gives the prospective old age dependency ratio, while the third column provides the conventional ratio. With increases in life expectancy, the prospective old age dependency ratios are, naturally, lower than the conventional ones and generally, rise at less than half their speed. The differences in 
time patterns of change are just as striking. In Germany, for example, the POADR reaches a peak in 2040 and then begins to fall. Forecasts after 2050 (not shown here) suggest that this fall will continue and that the peak in Germany's POADR will indeed come around 2040. The conventional old age dependency ratio shows no such peak. The two pictures of aging in Germany are quite different.

Table 2: $\quad$ Age at the onset of "Old Age Dependency", prospective old age dependency ratio, and the conventional old age dependency ratio, Germany, Japan, and the United States at ten year intervals from 2000 to 2050

\begin{tabular}{llll}
\hline & $\begin{array}{l}\text { Age at the Onset of } \\
\text { "Old Age Dependency" } \\
\text { (Prospective Age = 65) }\end{array}$ & $\begin{array}{l}\text { Prospective Old Age } \\
\text { Dependency Ratio }\end{array}$ & $\begin{array}{l}\text { Conventional Old Age } \\
\text { Dependency Ratio }\end{array}$ \\
\hline Germany & & & \\
2000 & 65.0 & 0.261 & 0.261 \\
2010 & 66.7 & 0.295 & 0.335 \\
2020 & 68.4 & 0.283 & 0.375 \\
2030 & 70.1 & 0.310 & 0.504 \\
2040 & 71.8 & 0.377 & 0.609 \\
2050 & 73.4 & 0.369 & 0.650 \\
Japan & & & \\
2000 & 65.0 & 0.276 & 0.276 \\
2010 & 66.6 & 0.334 & 0.380 \\
2020 & 68.1 & 0.419 & 0.518 \\
2030 & 69.6 & 0.423 & 0.576 \\
2040 & 71.2 & 0.436 & 0.729 \\
2050 & 72.8 & 0.507 & 0.866 \\
United States & & & \\
2000 & 65.0 & 0.199 & 0.199 \\
2010 & 66.3 & 0.183 & 0.203 \\
2020 & 67.7 & 0.205 & 0.265 \\
2030 & 69.1 & 0.247 & 0.346 \\
2040 & 70.5 & 0.258 & 0.377 \\
2050 & 72.0 & 0.242 & 0.399 \\
\hline
\end{tabular}

Notes: Forecasts are based on the mean values of the distributions of fertility, mortality, and migration in Sanderson and Scherbov (2005).

Age at the onset of "old age dependency" is computed so that remaining life expectancy remains constant at its level in 2000 for 65 year olds.

The conventional old age dependency ratio is the ratio of people at age $65+$ to those 20 to 64

The prospective old age dependency ratio is the ratio of the number of people at the age of onset of "old age dependency" or older to the number of people between 20 and the onset age. 
The same is true of the United States. Its POADR peaks around 2040 and then declines. Indeed, the POADR changes little between 2030 and 2050. This pattern is not seen in the conventional old age dependency rate. It continues to increase between 2030 and 2050. In Japan, the time patterns of change are also quite different, although there is no evidence of a peak in the POADR there.

The aging of populations will produce challenges. Some of these will be fiscal, with increased spending on pensions and medical care. As life expectancies increase, normal pension ages are rising in a number of countries and the expensive medical care in the last years of life is getting postponed to ever later ages. Using the conventional old age dependency rate as an indication of the extent of and the problems associated with population aging exaggerates future difficulties and can provide policy-makers with misleading information. A better way to understand the challenges of an aging population is to supplement our notion of age with one that takes into account future changes in life expectancy.

\section{Conclusions}

Traditional measures of population aging, such as the change in the median age and the change in the conventional old age dependency ratio, provide a highly incomplete picture of aging and can result in poorly designed policies. The median age is a backward-looking measure of age. We have proposed that median age be supplemented with a forward-looking measure, prospective median age. Further, we have suggested that an additional old age dependency ratio be added to our toolkit, one in which the old age dependency ratio is redefined with a constant prospective age as the point where "old age dependency" is assumed to begin. More broadly, we maintain that the best way to understand population aging is to treat age in two different dimensions, one backward-looking and one-forward looking.

The computation of prospective age requires life tables. In order to demonstrate that prospective age is useful as well as analytically interesting, we needed to show it is not sensitive to whether period or cohort life tables were used in its calculation. We demonstrated this analytically in Section 3, with historical data for Sweden and England and Wales in Section 4, and with population forecasts in Section 5. The recent histories of population aging in 28 countries presented in Section 6 showed that the movements in prospective median age do not just duplicate those in the median age and provide new information about the process of population aging.

In Section 7, we computed new life expectancy adjusted old age dependency ratios and showed that the conventional ratios and the new ones differed significantly in the pictures of population aging that they portray. 
The concept of prospective age and expected remaining years of life can both be used as forward-looking measures. We did this in Sanderson and Scherbov (2005). Even when period and cohort life tables differ, as they have in the past and undoubtedly will do in the future, we have shown there is a robust way to study population aging, and that is through the application of the concept of prospective age.

We believe that the approach will be useful in sociology and economics, where it can be used to study the timing of life cycle events, such as retirement. Because prospective age is a time-horizon consistent age, it can be readily integrated into many economic models. Changes in median prospective ages might also be helpful in forecasting changes in savings and investment behavior, the school attendance of older people, and the cost of health care.

\section{Acknowledgement}

The authors would like to thank the anonymous referees for very insightful and helpful comments. 


\section{References}

Bongaarts, J. and G. Feeney 2002. "How Long Do We Live?" Population and Development Review 28(1): 13-29.

2003. "Estimating mean lifetime." Proceedings of the National Academy of Sciences of the United States of America 100(23): 13127-13133.

Commission of the European Communities. 2005. "Confronting demographic change: a new solidarity between generations." Green paper, COM (2005) 94 final, Brussels, March 16. Downloaded from

http://www.europa.eu.int/comm/employment_social/news/2005/mar/comm200594_en.pdf .

Ezrati, Milton. 1997. “Japan's aging economics,” Foreign Affairs 76(3): 96-104.

Gavrilov, L. A. and P. Heuveline .2003. "Aging of Population", in P. Demeny and G. McNicoll, eds._The Encyclopedia of Population. New York: Macmillan Reference USA. Volume 1: 32-37.

Goldstein, J. R. and K. W. Wachter. 2005. "Gaps and Lags: Relationships Between Period and Cohort Life Expectancy", unpublished paper. March 22.

Hersch, L. 1944. "De la démographie actuelle à la démographie potentielle", in Melange des Études Economiques Offertes à William Rappard. [The author], Geneva.

Horiuchi, S. 2005. "Tempo Effect on Age-Specific Death Rates." Demographic Research 13-8: 184-200.

Human Mortality Database. University of California, Berkeley (USA), and Max Planck Institute for Demographic Research (Germany). Available at www.mortality.org or www.humanmortality.de (data downloaded on March 1, 2005 and on November 1, 2006).

Kotlikoff, Laurence J. and Scott Burns. 2004. The coming generational storm: what you need to know about America's economic future. Cambridge, MA.: Massachusetts Institute of Technology.

Lutz, W., W. Sanderson, and S. Scherbov. 2001. "The end of world population growth." Nature 412(6846): 543-545.

Lutz, W., W. Sanderson, and S. Scherbov. 2004. "The End of World Population Growth", in W. Lutz, W. C. Sanderson and S. Scherbov eds._The End of World 
Population Growth in the 21st Century: New Challenges for Human Capital Formation and Sustainable Development. London, Earthscan: 17-84.

Miller, T. 2001. "Increasing longevity and Medicare expenditures." Demography 38(2): 215-226.

Oeppen, J. and J. W. Vaupel. 2002. "Demography - Broken limits to life expectancy", Science 296(5570): 1029-1031.

Panush, N. and E. Peritz. 1996. "Potential Demography," European Journal of Population 12(1): 27-39.

Ryder, N. 1975. “Notes on Stationary Populations," Population Index 41(1):3-28.

Sanderson, W. and S. Scherbov. 2004. "Putting Oeppen and Vaupel to Work: On the Road to New Stochastic Mortality Forecasts", International Institute for Applied Systems Analysis, Interim Report IR-04-049.

2005. "Average remaining lifetimes can increase as human populations age", Nature 435(7043): 811-813.

Seshamani, M. and A. Gray. 2004. "Time to death and health expenditure: an improved model for the impact of demographic change on health care costs", Age and Ageing 33(6): 556-561.

Stearns, S. C. and E. C. Norton. 2004. "Time to include time to death? The future of health care expenditure predictions", Health Economics 13(4): 315-327.

Torres Joerges, X. and Núñez Garcés, M., no date, [Online], "Morbidity and mortality in Finland based on parish death-cause registers from 1750-1850", www.lifecouresincontext.n1/documents/paper_d_joerges_nunez.doc, downloaded February 28, 2006.

Yang, Z., E. C. Norton, and S. C. Stearns. 2003. "Longevity and health care expenditures: The real reasons older people spend more", Journals of Gerontology Series B-Psychological Sciences and Social Sciences 58(1): S2S10.

Zweifel, P., S. Felder, and A. Werblow. 2004. "Population ageing and health care expenditure: New evidence on the "red herring", Geneva Papers on Risk and Insurance-Issues and Practice 29(4): 652-666. 


\section{Appendix A}

Goldstein and Wachter (2005) investigate the case where adult mortality hazard rates take on the Gompertz form $h(a, t)=\alpha \cdot e^{-k t} \cdot e^{\beta \cdot a}$, where $h(a, t)$ is the hazard rate at age $a$ in year $t$, and $\alpha, \beta$, and $k$ are parameters (see Goldstein and Wachter (2005), equation 17). In period life tables the ratio of hazard rates at adjacent ages, $\frac{h(a+1, t)}{h(a, t)}$, is $e^{\beta}$. In cohort life tables the ratio of hazard rates at adjacent ages, $\frac{h(a+1, t+1)}{h(a, t)}$, is $e^{\beta-k}$.

Given those Gompertz adult hazard rates Goldstein and Wachter (2005) (in their equation (21)) show that period life expectancy at an adult age, for example age $a$, can be written:

$$
e_{p}(a, I)=r \cdot(I-b)+k_{b}(a),
$$

where $e_{p}(a, I)$ is life expectancy at age $a$ in index year $I, r$ is the annual rate of increase of life expectancy at age $a$ and $k_{b}(a)$ is life expectancy at age $a$ in the base year $b$. The base year can be any year including the index year and the standard year. Given the Gompertz hazard rates, $r$ is a constant and is equal to $\frac{k}{\beta}$.

Life expectancy at the period prospective age $A_{p}$ in the standard year $S$ can be written as:

$$
e_{p}\left(A_{p}, S\right)=r \cdot(S-b)+\Delta_{S, p} \cdot\left(A_{p}-a\right)+k_{b}(a),
$$

where $\Delta_{S, p}=\frac{e_{p}\left(A_{p}, S\right)-e_{p}(a, S)}{A_{p}-a}$. Note that $\Delta_{S, p}$ is a negative number.

Period prospective age is computed by equating (A1) and (A2) and solving this equation for $A_{p}$ :

$$
A_{p}=a+\left(\frac{r}{-\Delta_{S, p}}\right) \cdot(S-I) .
$$

Using the Goldstein and Wachter equation for the cohort life expectancy of an adult of age $a$ in year $I$ (see their equation (23)), we can write: 


$$
e_{c}(a, I)=\left(\frac{r}{1-r}\right) \cdot(I-b)+f(r, a, b)
$$

where $b$ is the base year, $f(r, a, b)$ is a function of $r, a$, and $b$, but is constant over time. People who are $a$ years old in year $I$ were born in year $I-a{ }^{16}$ People at the cohort prospective age of $A_{c}$ in the standard year $S$, were born in year $S$ - $A_{c}$. So first we write down the expression for the cohort life expectancy of people of age $a$ who were born in the year $S-A_{c}$ using equation (A4). Those people are of age $a$ in year $S-A_{c}+a$.

$$
e_{c}\left(a, S-A_{c}+a\right)=\left(\frac{r}{1-r}\right) \cdot\left(S-A_{c}+a-b\right)+f(r, a, b) .
$$

The cohort life expectancy of people of age $A_{c}$ in the standard year $S$ can now be expressed as:

$$
e_{c}\left(A_{c}, S\right)=\left(\frac{r}{1-r}\right) \cdot\left(S-A_{c}+a-b\right)+\Delta_{S, c} \cdot\left(A_{c}-a\right)+f(r, a, b),
$$

where $\Delta_{S, c}=\frac{e_{c}\left(A_{c}, S\right)-e_{c}\left(a, S-A_{c}+a\right)}{A_{c}-a}$.

Equating (A5) and (A6) and solving the equation for $A_{c}$, we get:

$$
A_{c}=a+\left(\frac{r}{-\Delta_{S, c} \cdot(1-r)+r}\right) \cdot(S-I) \text {. }
$$

The only difference between the equations for period prospective age (A3) and cohort prospective age (A7) is in the coefficients of the $S$-I term and this difference is almost always quite small. This can be seen from Table A1, where we have computed

\footnotetext{
${ }^{16}$ From equations (A1) and (A4) it can be seen that cohort life expectancy at age $a$ changes more rapidly than period life expectancy at that age. An increase in the year from 1999 to 2000, for example, would be associated with an $r$ year increase in life expectancy at age $a$. A one year increase in the birth cohort from 1969 to 1970, for example, would be associated with an $\left(\frac{r}{1-r}\right)$ year increase in life expectancy at age $a$.

For example, if the period increase in life expectancy at age $a$ was 0.2 years per calendar year, then the cohort increase in life expectancy at age $a$ would be 0.25 years per calendar year.
} 
the coefficients of the $S$-I terms for various possible prospective ages for the standard years 1840 and 1940, and for values of $r$ equal to 0.1 and 0.25 .

Table A1: Coefficients of (S-I) Terms in Equations (A3) and (A7) for Various Possible Prospective Ages and for Two Values of $\mathbf{r}$

\begin{tabular}{|c|c|c|c|c|c|c|c|c|}
\hline $\begin{array}{l}\text { Possible Values } \\
\text { of Prospective Age } \\
(a=25)\end{array}$ & $\begin{array}{l}S=1940 \\
r=0.1\end{array}$ & & $r=0.25$ & & $\begin{array}{l}S=1840 \\
r=0.1\end{array}$ & & $r=0.25$ & \\
\hline & Period $^{a}$ & Cohort $^{b}$ & Period $^{a}$ & Cohort $^{\mathrm{b}}$ & Period $^{a}$ & Cohort $^{\mathrm{b}}$ & Period $^{\mathrm{a}}$ & Cohort $^{\text {b }}$ \\
\hline 30 & 0.111 & 0.115 & 0.277 & 0.280 & 0.133 & 0.134 & 0.332 & 0.316 \\
\hline 35 & 0.111 & 0.117 & 0.277 & 0.285 & 0.135 & 0.138 & 0.338 & 0.324 \\
\hline 40 & 0.111 & 0.118 & 0.278 & 0.286 & 0.137 & 0.139 & 0.344 & 0.326 \\
\hline 45 & 0.112 & 0.119 & 0.279 & 0.288 & 0.140 & 0.139 & 0.349 & 0.326 \\
\hline
\end{tabular}

Notes: The coefficients were derived from data for Swedish females taken from the Human Mortality Database.

${ }^{a}$ Coefficient of $(S-I)$ in equation (A3).

${ }^{\mathrm{b}}$ Coefficient of $(S-I)$ in equation (A7).

\section{Appendix B}

The prospective age of a person at any age $a$ depends on the standard year chosen. Similarly, prospective median age is dependent on the standard. One's age and one's prospective age are the same in the standard year as are the median age and the prospective median age. Figure B1 shows the median ages of Japanese females from 1947 through 2004 and the prospective median ages for those years based on four standards, 1947, 1960, 1980, and 2000. As can be seen from that graph the time series move up or down by an amount that is close to being constant in order to ensure that the median age and the prospective median age intersect in the standard year.

The near constancy of the differences in the prospective median age curves across standards holding the calendar year constant is exactly what we would expect from the Gompertz formulation in Appendix A. Equation (A3) implies this because $\Delta_{S, p}$ is close to being constant in the age range that is relevant here.

A difference between an age in a given year and the corresponding prospective age is standard dependent. The same is true for median ages and prospective median ages. Changes over time in those differences are generally quite robust to the choice of a standard in cases where mortality rates are not affected by unusual conditions, such as a severe epidemic. 
Figure B1: The Median Age of Japanese Females and their Prospective Median Ages using Standards from 1947, 1960, 1980, and 2000.

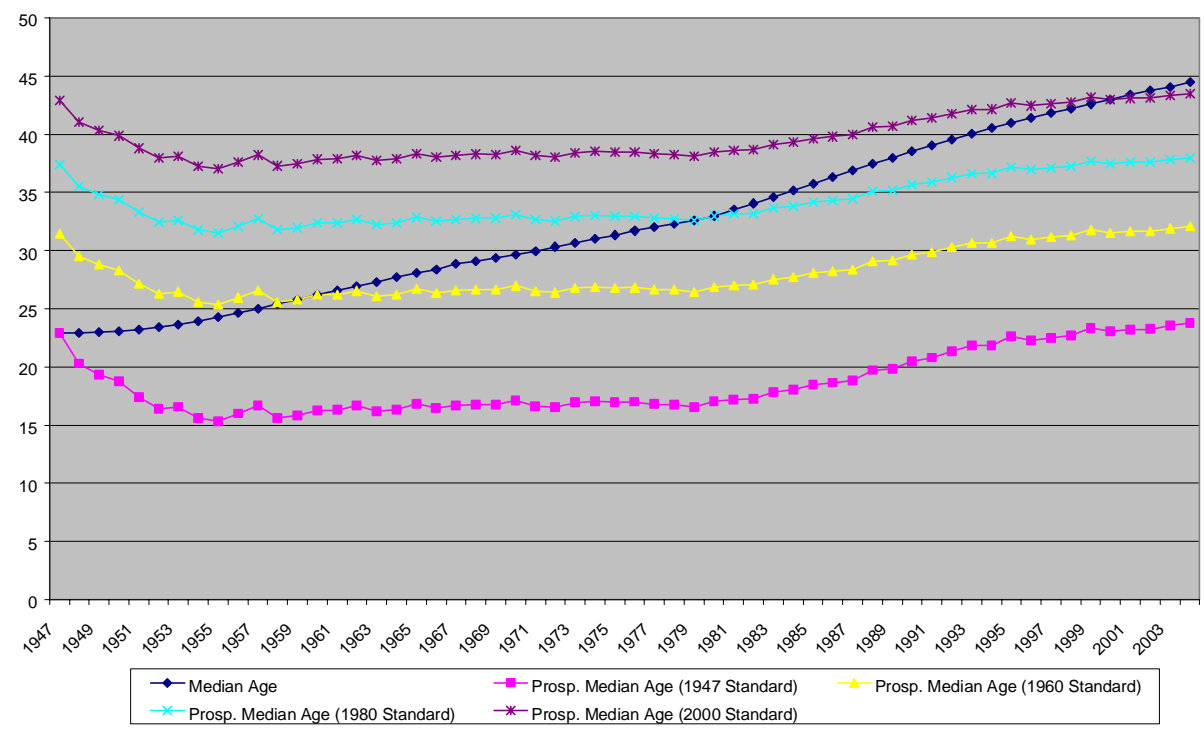


Sanderson \& Scherbov: A new perspective on population aging 